\title{
Liderança transformacional na enfermagem
}

\author{
Transformational leadership in nursing \\ Liderazgo de cambio en enfermería
}

\author{
Maria Rejane Strapasson', Cássia R. G. Medeiros' \\ 'Centro Universitário UNIVATES. Lajeado, RS
}

Submissão: $29 / 10 / 2007$

Aprovação: 29/1 1/2008

\section{RESUMO}

Este estudo Qualitativo objetivou verificar se os pressupostos da Liderança Transformacional estão presentes na prática de enfermeiros de um hospital de médio porte do interior do Rio Grande do Sul. Os sujeitos foram 11 enfermeiros chefes de diversos setores do hospital que trabalham há um ou mais anos na Organização pesquisada. O instrumento utilizado foi uma entrevista semi-estruturada. Os dados foram analisados por meio do método de análise de conteúdo, do Qual emergiram 5 categorias: significado de liderança; habilidades essenciais para o exercício da liderança; exercício das habilidades de liderança no cotidiano dos enfermeiros; participação da Organização no desenvolvimento da liderança; e resistência dos enfermeiros ao processo de mudança. Verificou-se Que alguns dos pressupostos são identificados e percebidos como importantes, embora não estejam totalmente presentes no cotidiano dos enfermeiros. Descritores: Enfermagem; Liderança; Gerência.

\begin{abstract}
This Qualitative research aimed at verifying if the presuppositions of Transformational Leadership are present in the nurses practice in a medium size hospital in the countryside of Rio Grande do Sul. The researched people were eleven head nurses in different sectors of the hospital, who have been working for one year or more in the inquired medical institution. The tools used for the research was a semistructured interview. The data have been analysed through content analyses method, in which five categories emerged: the meaning of leadership; essential abilities for leadership activity; leadership ability in everyday nurse activity; participation of the Institution in leadership development; and the resistance of nurses to the changing process. Some of the presuppositions are identified and noticed as important, although not totally present in everyday activity of nurses.
\end{abstract}

Descriptors: Nursing; Leadership; Management.

\section{RESUMEN}

Este estudio cualitativo tuvo por objetivo verificar si los conceptos de Liderazgo de Cambio están presentes en la práctica de enfermería de un hospital mediano, del interior de Rio Grande do Sul. Los sujetos han sido 11 enfermeros jefes de los diversos sectores del hospital, Que trabajan hace uno o más años en la organización investigada. El instrumento utilizado ha sido una entrevista semiestructurada. Los datos han sido analisados a través del método de análisis de contenido, del cual surgieron 5 categorías: significado de liderazgo; habilidades esenciales para el ejercicio del liderazgo; ejercicio de las habilidades de liderazgo en las acciones a diario de los enfermeros; participación en la organización en el desarrollo del liderazgo; y resistencia de los enfermeros al proceso de cambios. Se ha verificado Que algunos de los conceptos son identificados y percibidos como importantes, aunque no estén totalmente presentes en las acciones a diario de los enfermeros.

Descriptores: Enfermería; Liderazgo; Gerencia. 


\section{INTRODUÇÃO}

Ao longo da história as organizações de saúde, especialmente os hospitais vêm sofrendo com as mudanças paradigmáticas, exigindo uma transformação em seu cenário social, político e econômico pós-moderno. Nesse contexto a enfermagem é parte integrante desse processo, uma vez Que, além de desenvolver a ação de cuidar, realiza a atividade de administrar, assumindo o gerenciamento do serviço ${ }^{(1)}$.

Nessa realidade a liderança vem sendo exigida nas organizações de saúde passando de um modelo hierarquizado e tradicional para um trabalho mais flexível, em equipe, com unidades semiautônomas, construídas a partir de uma relação de poder e confiança mútua, tornando-se indispensável o papel do enfermeiro, elemento da equipe Que privilegia os interesses coletivos e oferece assistência segura ao paciente ${ }^{(2)}$.

No início dos anos 80 , surgiu a chamada nova perspectiva de liderança, Que se diferencia pelas idéias de gestão pelo simbólico, envolvendo a Liderança Transformacional ${ }^{(3)}$.

Na nova tendência, as organizações de saúde são chamadas a ancorar-se na Liderança Transformacional, por ser considerada o paradigma da mudança pós-moderna. Essa liderança é definida como um estilo de liderança voltada para a Qualidade da atenção à saúde prestada pela enfermagem, sobretudo na gerência, na educação e na assistência ${ }^{(4)}$.

Neste novo estilo, o líder transformacional tem paixão por um ideal, inspira e motiva seus liderados a transcender seus próprios interesses para o bem da organização, modificando sua visão sobre as coisas, ajudando-os a pensar nos problemas de nova forma. São capazes de entusiasmar e estimular a darem o máximo de si para alcançar os objetivos da equipe. Eles oferecem consideração individualizada e promoção intelectual a seus liderados, além de possuírem carisma $^{(5)}$.

Neste estudo buscou-se verificar se os pressupostos dessa liderança estão presentes na prática de enfermeiros de um hospital de médio porte, contemplando os seguintes objetivos específicos: verificar o estilo de liderança dos enfermeiros de um hospital de médio porte; identificar se a cultura organizacional favorece a prática da Liderança Transformacional; e investigar se a organização estimula o desenvolvimento de lideranças.

\section{Liderança em Enfermagem}

A liderança é definida como a capacidade de influenciar um grupo, a fim de buscar e alcançar objetivos. Essa influência pode ser formal, como a conferida por um alto cargo na organização, no Qual a pessoa pode assumir um papel de liderança apenas em função do cargo Que ocupa, ou pode surgir naturalmente de dentro de um grupo $^{(5)}$.

A temática liderança pode ser classificada e agrupada em categorias: as características do líder, Qualidades natas até os anos 40; a perspectiva do estilo comportamental até os anos 60; a abordagem contingencial ou situacional até início dos anos 80; e as idéias da gestão pelo simbólico, envolvendo a Liderança Carismática, a Liderança Visionária e a Liderança Transformacional ${ }^{(3)}$.

Cabe esclarecer que a Liderança Comportamental é aquela Que propõe comportamentos específicos que diferenciam os líderes dos liderados, podendo ser orientados para as tarefas ou para as pessoas, denominados de estilo autoritário, democrático e laissez-faire ${ }^{(5)}$.

lá a Liderança Contingencial ou Situacional compreende o comportamento do líder, assim como os fatores situacionais do contexto. Dessa forma, o estilo de liderança resulta não apenas das características dos indivíduos, mas também do contexto ${ }^{(3)}$. Contudo, a teoria da contingência depende da adequação entre o estilo do líder em interagir com seus liderados e o Quanto de influência a situação proporciona, incluindo o trabalho, a cultura organizacional, o nível de apoio do grupo, a experiência do líder, o nível de estresse e as características dos liderados como personalidade, capacidade e motivação ${ }^{(5)}$.

Os líderes carismáticos, por sua vez, desenvolvem um carisma, possuem uma visão otimista e entusiasta, comunicam-se por meio do comportamento e são capazes de influenciar seus liderados assumindo uma postura de confiança e sensibilidade frente às limitações do ambiente e das necessidades da equipe, despertandoIhes um sentimento de auto-estima e autoconfiança ${ }^{(5)}$.

E a Liderança Visionária é tida como a capacidade de criar e articular uma visão de futuro atrativa e possível para a organização, despertando talentos, habilidades e providenciando recursos para Que se concretize ${ }^{(5)}$.

Quanto à Liderança Transformacional, esta leva líderes e liderados a níveis altos de motivação, atribuindo uma visão de futuro capaz de fortalecer e influenciar outros ${ }^{(6)}$.

A Liderança Transformacional é uma relação baseada na confiança, Que influencia de forma positiva líder e liderados, tornando as metas e objetivos da organização um propósito coletivo. O líder transformacional conhece a cultura e os valores da organização, valoriza a criatividade e a inovação e estimula para a mudança, busca cultivar esses valores e comportamentos em seu corpo funcional ${ }^{(6)}$.

Compreende-se também Que o líder transformacional oferece consideração individualizada, presta atenção às preocupações e necessidades de seus liderados. É capaz de entusiasmar e inspirar as pessoas a darem o máximo de si em benefício do grupo, transmite a visão e o sentido da missão, comunicando suas expectativas, além de possuir carisma. Esse estilo de liderar está relacionado a índices baixos de rotatividade, maior produtividade e satisfação dos funcionários ${ }^{(5)}$.

Com base nessas premissas acredita-se Que a visão é a essência da Liderança Transformacional e implica na capacidade de vislumbrar determinada situação futura e de descrevê-la ao outros, para Que comecem a "compartilhar o sonho"(6). Nesse sentido, a Liderança Transformacional é relevante em função da importância atribuída, uma vez Que promove a auto-eficácia da equipe, a Qualidade da assistência e atende aos objetivos da organização.

\section{METODOLOGIA}

O presente estudo trata-se de uma peseuisa com abordagem Qualitativa. Foi desenvolvida em um hospital privado de médio porte, com 118 leitos, localizado em um município no interior do Rio Grande do Sul, Que presta assistência em diversas especialidades e apóia o ensino e a pesquisa. Os sujeitos foram enfermeiros, líderes de diversos setores do hospital Que trabalham há um ou mais anos na Organização peşuisada. Utilizou-se, para coleta de dados, a entrevista semi-estruturada, contendo um roteiro com três Questões 
sobre as habilidades que o enfermeiro considera essencial para o exercício da liderança; como está sendo o exercício destas habilidades no cotidiano dos enfermeiros e a participação da organização no desenvolvimento da liderança. A análise e a interpretação dos dados fundamentaram-se no método de análise de conteúdo proposto por $\operatorname{Bardin}^{(7)}$.

O projeto foi aprovado pelo Comitê de Ética em Pesquisa da UNIVATES, com o número CEP 019/07, conforme prevê a Resolução no 196/96 ${ }^{(8)}$. Os sujeitos assinaram o Termo de Consentimento Livre e Esclarecido. Para garantir o sigilo da identidade dos pesquisados, seus nomes foram substituídos pela letra "E" (enfermeiro) seguida do número correspondente à ordem do depoimento prestado (EI,E2,E3...).

\section{RESULTADOS E DISCUSSÃO}

A amostra pesquisada constituiu-se de 11 enfermeiras líderes de diferentes setores do hospital analisado, com idade entre 27 e 44 anos. Sete possuem pós-graduação em diversas áreas da enfermagem, sendo uma na área de gestão. Em relação ao tempo de atuação na Organização, 9 enfermeiras atuam entre 1 a 4 anos e 2 estão há mais de dez anos na Instituição. Na análise de conteúdo emergiram cinco categorias: significado de liderança; habilidades essenciais para o exercício da liderança; exercício das habilidades de liderança no cotidiano dos enfermeiros; participação da Organização no desenvolvimento da liderança; e resistência ao processo de mudança.

\section{Significado de Liderança}

A liderança é tida como uma das principais competências a ser desenvolvida pelo profissional da enfermagem, pois no trabalho em equipe os enfermeiros deverão estar aptos a assumir posições de liderança. Nesse contexto, o líder é envolvido pelo compromisso, responsabilidade, empatia, habilidade para a tomada de decisões, comunicação e gerenciamento de forma efetiva e eficaz, Qualificando o serviço e atendendo as expectativas da organização ${ }^{(12)}$.

O tema gerou nos pesquisados reações como riso, medo, inQuietação, demonstrando ser um assunto complicado e difícil de ser definido, como retratam as ponderações a seguir:

"É um tema complexo. Ai! (riso). É difícil... definir isso" (EI).

“Liderança! A palavra é mais amedrontadora do Que realmente vem a ser a liderança" (E3).

Quatro entrevistadas definiram a liderança como algo nato na pessoa, acreditando em um potencial inicial Que, se desenvolvido, pode fazer com que o indivíduo capacite-se para a liderança, como exemplifica a fala:

A Questão de liderança ou ela é nata sua, você acabou desenvolvendo durante sua educação, ou isso já vem ainda de berço, e tem coisas que você pode estar adequando, pode estar melhorando através de literatura, de palestras, claro com outros profissionais (E2).

Outras participantes do estudo definem liderança como uma ação de influenciar pessoas, ligada a um processo de equipe Que tem um objetivo a ser alcançado, como segue:

"Acho que a liderança é saber conduzir teu grupo, tu ser uma pessoa ágil, tu ter visão. Liderança é isso, trabalho de grupo, uma pessoa que saiba dar um retorno pra instituição independente do ambiente onde tu estejas" (E3).

Segundo Gardner, "a liderança é definida como o processo pelo Qual um grupo é induzido a dedicar-se aos objetivos defendidos e partilhados pelo líder e seus seguidores"(12).

Nesse sentido, Simões comenta Que a liderança proporciona o encontro de diferentes pessoas e profissionais no trabalho em equipe, desafiando o enfermeiro a desenvolver habilidades de ouvir, relacionar-se bem com seus liderados, a fim de tê-los como aliados no processo de cuidar, conquistando assim sua autonomia profissional dentro da instituição, ampliando seu espaço de atuação( ${ }^{(9)}$.

A análise dos dados evidencia Que apenas uma pesquisada define liderança como a capacidade de comunicar-se, seguida de duas enfermeiras Que entendem liderança como a habilidade de motivar o grupo:

"Acho que a líder tem que ser uma pessoa bem comunicativa com todos, com a equipe" (E4).

\section{"I...] líder é alguém que tem que motivar os integrantes da} equipe" (EI).

Percebe-se nesse relato Que a motivação é entendida como algo possível de ser realizado pela influência externa, isto é, de uma pessoa para outra. No entanto, a motivação é um processo capaz de fornecer intensidade, direção e persistência aos esforços de uma pessoa, a fim de alcançar seus objetivos e as metas da organização ${ }^{(5)}$

A liderança também é entendida por entrevistadas como a capacidade de estabelecer regras e fazer com Que as pessoas sigam o caminho que o líder considera correto, ou seja,

\section{“[... ditar as normas, mostrar o caminho correto a seguir" (EI).}

\section{Habilidades Essenciais para o Exercício da Liderança}

"O conhecimento é insubstituível nas práticas de saúde"(16). Contudo, ele somente não é suficiente para Que os profissionais trabalhem com as pessoas, desenvolvam relacionamentos positivos e realizem uma leitura psicossocial do seu ambiente de trabalho ${ }^{(13)}$.

Quatro participantes definem o conhecimento teórico-prático e todos os processos e rotinas de enfermagem como sendo habilidades essenciais para o exercício da liderança. Confundem o exercício da liderança com a busca pelo conhecimento e a realização de procedimentos técnicos. Assim destacam:

“Conhecimento, não só sobre liderança, gerenciamento, mas sobre todos os processos envolvidos no serviço que tu trabalha, sobre todas as patologias, todas as rotinas" (EI).

"A prática é importante, porQue tu não pode cobrar uma coisa de alguém que tu não sabes fazer. Acho Que é importante tu 
saber fazer e depois saber cobrar." (E4).

Segundo Fernandes et $\mathrm{al}^{(13)}$, os enfermeiros não devem limitarse aos saberes técnico-instrumentais e intelectuais para o desenvolvimento do exercício de liderança e de uma prática interpessoal de qualidade. Suas habilidades residem na capacidade de identificar, mobilizar e pôr em prática os conhecimentos científicos pertinentes a situações concretas Que nem sempre são abordadas em livros. Para tanto, faz-se necessário algo mais: o emocional, o interpessoal e o organizacional se integrando.

Apenas uma enfermeira destacou a flexibilidade, a motivação e a visão como habilidades indispensáveis para a liderança, enfocandoos como facilitadores do processo.

Eu, hoje vejo a Questão da flexibilidade muito importante. Cada pessoa é um ser humano individual. Então você não pode usar uma linha e trabalhar com todos sobre o mesmo ponto de vista, porque aí tu acaba te frustrando e a tua equipe também fica frustrada (E2).

Outras habilidades, como a coerência, a comunicação, saber ouvir, o trabalho em equipe, relacionamento interpessoal, estiveram presentes na fala de cinco participantes da pesquisa, conforme exemplificam estas transcrições:

"Ser coerente, ser ouvinte, saber dar soluções ou então buscar onde está o problema, buscar junto com a equipe as soluções" (E5).

"Ter uma boa comunicação com eles, um bom entrosamento" (E8).

Braga $^{(12)}$ explica Que o enfermeiro líder precisa saber comunicarse e gerenciar a comunicação, pois a habilidade comunicativa é fundamental para Que este profissional conQuiste relações profissionais e pessoais mais significativas, com maior autoconsciência e aceitação das diferenças.

\section{Exercício das Habilidades de Liderança no Cotidiano}

Hoje o enfermeiro é desafiado a possuir a cultura de ser rápido, ter conhecimento, espírito de equipe, saber comunicar-se, estar disposto a aprender sempre, encontrar formas criativas e inovadoras de produzir e viver, ser ético e estético ${ }^{(10)}$.

Quanto ao exercício das habilidades de liderança no cotidiano dos enfermeiros, observou-se intensa preocupação com o controle, entendendo a liderança como imposição dos lideres sobre seus liderados. Nas palavras das entrevistadas,

"[... o pessoal está todo tentando ter uma postura mais firme frente aos funcionários." (EI).

"Tem Que ter mais pulso firme" (E5).

Em contraposição a este papel controlador, ditador de regras, normas e procedimentos, acredita-se Que o enfermeiro deve estar orientado para as possibilidades de desempenhar uma liderança mais orientada para o futuro, mais flexível, dinâmica e disposta a assumir riscos ${ }^{(14)}$.

Evidenciou-se a presença de sentimentos como insegurança Quanto à tomada de decisão, devido à ausência de clareza do Que a instituição espera dos enfermeiros e do Que estes buscam na organização, conforme retratam as falas:

“[...] alguns pontos de vista, instituição e grupo de enfermeiros, está um pouco não definido... o Que o enfermeiro também busca dentro da instituição" (E2).

"Tem colegas, assim como eu, a gente fica insegura, em cima do meu funcionário, até que ponto eu posso agir, o Que Que eu posso fazer. Qual é a minha autoridade?"(E5).

“|... não sabe se toma a decisão mais correta. Você fica um pouco insegura" (E7).

Drucker $^{(10)}$ acredita Que os enfermeiros têm dificuldade em reconhecer e delimitar Quais são suas funções em cada ambiente, sendo necessário este profissional encontrar seu "nicho" de atuação, em Que apenas seja suficiente indicar a tarefa, para que ele próprio determine, Quando, o Quê, para Quem, onde e por Quê fará.

As equipes potencializam-se Quando têm reconhecido o seu espaço de atuação, com mais autonomia, ampliação de conhecimentos e diálogo mais autêntico ${ }^{(I I)}$. "Em todos os níveis da organização, as pessoas precisam ter uma idéia de onde e para onde estão caminhando"(15).

Sete enfermeiras afirmaram desenvolver bem o exercício da liderança, expresso pela busca do conhecimento, do trabalho em grupo e do desenvolvimento de novas habilidades para gerenciar e liderar sua equipe. Para uma delas,

"[...] de uma maneira geral todas exercem muito bem e conseguem resolver os seus problemas de uma maneira muito tranQüila, assim, há uma resposta positiva sempre" (E3).

De acordo com Motta ${ }^{(14)}$, almejar um desempenho eficaz do enfermeiro, como líder da equipe de enfermagem, pressupõe a busca constante de comportamentos, conhecimentos e do desenvolvimento de habilidades essenciais para a liderança, as Quais envolvem Qualidades pessoais, habilidades interpessoais e o conhecimento do contexto organizacional.

Fernandes et $\mathrm{al}^{(13)}$ acreditam Que o relacionamento interpessoal não deve ser reduzido ao nível de uma teoria ou da implantação pura de conhecimentos ou procedimentos. A dimensão interpessoal transcende os limites da sofisticação tecnológica e se desenvolve por meio de relacionamentos, inferências, interpretações e criatividade em função de seu saber, de suas vivências, da visão situacional e das condições organizacionais de trabalho.

Quatro das entrevistadas relataram, contudo, ter dificuldade em liderar, expressando desejo de mudança no seu estilo de liderança. Elas afirmam:

"I...] acho Que, no geral, aqui os enfermeiros têm dificuldade em liderar" (E6).

[...] vejo o grupo com uma certa dificuldade, por vários fatores, 
pela Questão, Que já vem de muito tempo, de Que os enfermeiros não são tão respeitados, da Questão médica. Então são coisas Que acabam, muitas vezes, te tirando a autonomia [...] Eu sempre gostei de trabalhar assim: "Gurias, o Que vocês acham?" E assim tô buscando isso também, mas ao mesmo tempo com cobrança (EII).

“Estávamos nos tornando técnicos aperfeiçoados e perdemos o papel de liderança" (E2).

Lançando um olhar mais crítico sobre a enfermagem no contexto da Liderança Transformacional, confirma-se a necessidade de buscarse mecanismos Que rompam com a hegemonia médica, a submissão, a timidez, a falta de identidade dos profissionais, o uso inadequado do poder, a debilidade nos aportes técnico e administrativos e a falta de reconhecimento do seu papel por parte da população ${ }^{(4)}$.

Participação da Organização no Desenvolvimento da Liderança

Segundo Enrieuez ${ }^{(3)}$, a organização pode definir-se como um sistema cultural, simbólico e imaginário, em que se destacam o papel do sujeito, os processos grupais, a construção de seu imaginário social e de seu mundo de valores.

Torna-se evidente Que a valorização da vida e da autoorganização fortalecem e capacitam os indivíduos, criando ambientes de trabalho sadios nos Quais as pessoas sentem-se apoiadas e incentivadas na busca da realização dos seus próprios objetivos, sem terem Que sacrificar a própria integridade, a fim de atender as exigências da organização(15).

Nove enfermeiras asseveram Que a Organização estimula o exercício da liderança. Nos termos delas afirmam Que:

“Com certeza, tanto que colocou à disposição da gente um profissional Que está trabalhando bem esta Questão de gerenciar, de liderar" (EI).

"Acho que estão tentando fazer a parte deles, estimulando a gente a fazer cursos de treinamento" (E4).

As organizações estão se preocupando cada vez mais com os recursos humanos, pois estes se constituem em seu maior bem, uma vez Que é por meio deles Que suas metas e objetivos são alcançados. Nesse contexto, a liderança é reconhecida como um precioso instrumento $^{(4)}$.

Apenas duas entrevistadas apresentam outra visão. Uma relata Que somente a coordenadora estimula o exercício da liderança, não percebendo esta como representante da Organização. A outra observa Que a Organização está passando por um processo de aprimoramento no gerenciamento de enfermagem, Que está em fase inicial. Na fala delas:

"[...] se for a instituição em si não disse nada pra mim. [...] nossa coordenação de certa forma nos informou Que temos que ter liderança" (E5).

“Não vou te dizer que sempre foi assim. Está começando a ter agora. Isso é ótimo, ótimo, ótimo. As coisas vão ser mais claras, a gente vai saber como melhorar, conduzir situações" (E3).

\section{Resistência ao Processo de Mudança}

É comum ouvir Que nas organizações as pessoas resistem à mudança. Na verdade, não é à mudança Que elas resistem; resistem, sim, a uma mudança Que lhes é imposta. Os indivíduos são ao mesmo tempo estáveis e sujeitos à mudança e ao desenvolvimento, mas seus processos naturais de mudança são diferentes das mudanças organizativas projetadas e definidas ${ }^{(15)}$.

Outro fator significativo deste estudo foi a constatação de Que o processo de mudança gera conflito, Queixas, excessos e agitação, por mexer com sentimentos, valores e a própria cultura pessoal de cada indivíduo, como espelha a transcrição a seguir:

[...] desenvolver mudanças gera conflito muito grande. Não vou dizer que é fácil, mexer com todos grupos pessoais, de culturas tuas mesmo, teu jeito de trabalhar e então você começa a repensar tudo, sabe?[...] Quando tem uma mudança, às vezes tu peca por excesso (E2).

"A sensação de instabilidade crítica Que precede o surgimento da novidade pode causar incerteza, medo, confusão e a perda de autoconfiança”(15). Na economia global turbulenta da atualidade, torna-se relevante, pois as pessoas têm muito medo de perder o emprego em virtude de mudanças estruturais radicais, gerando uma forte resistência à mudança ${ }^{(15)}$.

O trabalho de enfermagem é, sobretudo, cooperativo e executado em equipe. Para tanto, a enfermeira deve buscar cultivar uma liderança libertadora e dialógica em todas as dimensões da conduta, a fim de promover a troca de saberes de enfermagem e individuais, Que privilegie valores, crenças e culturas de todas as categorias da equipe profissional ${ }^{(9)}$.

Assim sendo, ao longo do processo de mudança, é possível Que se rompam algumas das antigas estruturas, mas, na medida em Que se encontre um clima de apoio e elos bilaterais de comunicação, aumenta a possibilidade de surgirem novas e mais significativas organizações $^{(15)}$.

\section{CONSIDERAÇÕES FINAIS}

Neste estudo verificou-se Que o tema liderança desperta nos enfermeiros reações diversas, sendo definido como muito complicado e difícil.

Os enfermeiros entendem a liderança como a capacidade de influenciar a equipe, visando a atender aos objetivos da instituição, sendo necessário para isso o conhecimento técnico-científico e o desenvolvimento de habilidades humanas e interpessoais.

Quanto às habilidades essenciais para o exercício da liderança, pode-se inferir Que os entrevistados confundem conhecimento, rotinas e técnicas com liderança.

Na pesquisa fica evidente a existência de dificuldades em liderar no cotidiano de trabalho dos enfermeiros. Parecem estar sem referência, faltando clareza sobre o Que a Organização espera deles e vice-versa. Essa indefinição gera insegurança no Que se refere ao estilo de liderança a ser adotado. Isso talvez ocorra porQue a Organização está em processo de mudança, propondo novo perfil de enfermeiro, orientado para a liderança e o gerenciamento.

Os enfermeiros caracterizaram liderança como: motivar a equipe; desenvolver boa comunicação; ser ágil; ter visão; orientar e conduzir 
a equipe; buscar conhecimento; ter flexibilidade; ser confiável; respeitar a equipe; ter postura ética; ser coerente; ser bom ouvinte; tomar decisões; demonstrar segurança; ser honesto; estar ao lado da Organização e do funcionário; ter atitude e auto-confiança.

De acordo com o objetivo do estudo, verificou-se Que alguns dos pressupostos da Liderança Transformacional são identificados e percebidos pelos enfermeiros como importantes, embora ainda não estejam totalmente presentes no seu cotidiano.

O estímulo ao desenvolvimento intelectual e criativo da equipe é um dos pressupostos Que não apareceu nos relatos. Também a capacidade de comunicar aos liderados suas expectativas e as da Organização torna-se difícil, uma vez Que essas expectativas não estão claras para os próprios enfermeiros.
Assim sendo, percebe-se a necessidade de incluir a Liderança Transformacional como um tema transversal dentro dos currículos dos cursos de Enfermagem, instrumentalizando-os para o desenvolvimento pessoal e profissional para o mundo do trabalho e o desafio de gerenciar e liderar uma eQuipe.

As organizações também precisam investir na formação de lideranças, incentivando e implementando programas de capacitação e educação permanente.

Os enfermeiros en@uanto líderes devem buscar aperfeiçoar-se continuamente, aliando conhecimento técnico-científico e habilidades pessoais para liderar, correspondendo às expectativas da organização e da eQuipe, proporcionando uma prática mais crítica, reflexiva e participativa.

\section{REFERÊNCIAS}

1. Cardoso TV. O trabalho do enfermeiro: percepção dos dirigentes de hospitais de grande porte no município de Porto Alegre [dissertação]. Canoas: Faculdade de Enfermagem, Universidade Luterana do Brasil; 2002.

2. Gaidzinski R, Peres HC, Fernandes MFP. Liderança: aprendizado contínuo no gerenciamento em enfermagem. Rev Bras Enferm 2004: 57(4): 464.

3. Azevedo CS. Liderança e processos intersubjetivos em organizações públicas da saúde. Ciência Saúde Coletiva 2002; 7(2): 349-61.

4. Neto DL. Liderança Transformacional: a arte de administrar com inteligência emocional. Administr Nursing 2000. Disponível em: http://www.ibict.br

5. Robbins SP. Comportamento organizacional. $9^{\mathrm{a}}$ ed. São Paulo: Prentice Hall; 2002.

6. Marquis $\mathrm{BL}$, Huston $\mathrm{Cl}$. Administração e liderança em enfermagem: teoria e prática. $4^{\mathrm{a}}$ ed. Porto Alegre: Artmed; 2005.

7. Bardin L. Análise de conteúdo. 3a ed. Lisboa: Edições 70; 2004.

8. Ministério da Saúde (BR). Conselho Nacional de Saúde. Resolução $n^{\circ} 196$, de 10 de outubro de 1996. Diretrizes e normas regulamentadoras de pesquisas envolvendo seres humanos. Disponível em: http://conselho.saude.gov.br/docs/ Resol96.doc

9. Santos I, Oliveira SRM, Bittencourt C. Gerência do processo de trabalho em Enfermagem: liderança da enfermagem em unidades hospitalares. Texto Contexto Enferm 2006; 15(3): 393-400.

10. Deisvald J, Lunardi Filho W, Gomes G. Apropriação e uso de conhecimentos de gestão para a mudança de cultura na Enfermagem como disciplina. Texto Contexto Enferm 2006; 15(4): 500-07.

1 1. Erdmann A, Andrade RS, Ferreira SLM, Meirelles SHB. Gestão das práticas de saúde na perspectiva do cuidado complexo. Texto Contexto Enferm 2006; 15(3): 483-91.

12. Peres MA, Trendo HMC. Gerência e competências gerais do enfermeiro. Texto Contexto Enferm 2006; 15(3): 492-9.

13. Fernandes DI, Araújo AF, Fernandes I, Reis SL, Gusmão CM, Santana N. Competência interpessoal nas práticas em saúde. Texto Contexto Enferm 2003; 12(2): $210-5$.

14. Simões ALA, Neide F. O desafio da liderança para o enfermeiro. Rev Latino-am Enfermagem 2003; 11 (5): 567-73.

15. Capra F. As conexões ocultas: ciências por uma vida sustentável. São Paulo: Editora Cultrix; 2002. 